\title{
PÁTRIA EDUCADORA E FECHAMENTO DE ESCOLAS DO CAMPO: O CRIME CONTINUA
}

\author{
EDUCATOR HOMELAND AND THE COUNTRYSIDE SCHOOLS SHUTDOWN: THE \\ CRIME GOES ON \\ PAÍS EDUCADOR Y CLAUSURA DE LA ESCUELA DE CAMPO: CRIMEN CONTINUA
}

Antonio Munarim** antoniomunarim@gmail.com

REVISTA PEDAGÓGICA

Revista do Programa de Pós-graduação em Educação da Unochapecó | ISSN 1984-1566

Universidade Comunitária da Região de Chapecó | Chapecó-SC, Brasil

Como referenciar este artigo: TAFFAREL, C. Z.; MUNARIM, A. Pátria educadora e fechamento de escolas do campo: o crime continua. Revista Pedagógica, Chapecó, v. 17, n. 35, p. 41-51, maio/ago. 2015.

\begin{abstract}
RESUMO: O presente texto apresenta evidências do crime contra a classe trabalhadora, com o fechamento de escolas do campo, em meio ao discurso sobre a Pátria Educadora e argumentos sobre a tática a ser desenvolvida para reverter este processo que não permitirá que os problemas do analfabetismo, acesso, permanência, estrutura e financiamento das escolas sejam resolvidos nos próximos anos. O texto parte de uma encomenda ocorrida durante a realização da primeira reunião da Comissão Nacional Pedagógica do Pronera/Incra/MDA, em Brasília-DF, no período de 15 a 18 de julho de 2015, e encomenda do Editor Chefe do presente periódico, sobre o documento estratégico da Secretaria de Assuntos Estratégicos do Governo Federal e o lema adotado pela presidenta Dilma Rousseff em seu segundo mandato Pátria Educadora. O texto se situa, também, entre os que disputam posições em todos os espaços onde se fizerem necessárias as lutas em defesa das reivindicações dos trabalhadores, organizados em movimentos populares, em especial no campo brasileiro.
\end{abstract}

PALAVRAS-CHAVE: Educação rural. Escolas do campo. Orçamento Geral da União. Movimento de Educação do Campo.

ABSTRACT: This paper presents evidence of the crime committed against the working class, illustrated by the countryside schools shutdown amid the speech about Educator Homeland. Arguments and tactics have been developed to reverse the process which is not going to allow illiteracy, access, permanence, structure and funding problems to be solved in the following years. The text came from a order occurred during the first meeting of the National Pedagogical Commission of Pronera/Incra/MDA in Brasilia, DF, Brazil, from 15 to 18 July 2015, and the order required by the Chief Editor of this journal on the Strategic Issues Secretariat of the Federal Government, that includes the slogan proposed by President Dilma Rousseff in hers second term -Educator Homeland. This wording also stands for those who run for positions in all the sectors where the struggle for workers's claims are necessary, constantly organized in the form of popular movements, especially in Brazilian countryside.

KEYWORDS: Countryside Education. Countryside Schools. Federal Budget. Countryside Education Movement.

RESUMEN: Este trabajo presenta la evidencia del crimen contra la clase obrera, con el cierre de escuelas del campo, en medio de rumores de país Educador y argumentos sobre tácticas siendo desarrollado para revertir este proceso que no permitirá que los problemas de analfabetismo, el acceso, la permanencia, la estructura y la financiación de las escuelas se resuelva en los próximos años. La parte del texto de un orden que se produjo durante el transcurso de la primera reunión de la Comisión Pedagógica Nacional de PRONERA/ INCRA/MDA em Brasília-DF del 15 al 18 julio de 2015, y el Editor Jefe de la revista en papel la estrategia de la Secretaría Asuntos Estratégicos del Gobierno Federal y el lema adoptado por la presidenta Dilma Rousseff em su segundo mandato - País Educador. El texto se detiene entre las posiciones con tendientes en todas las áreas donde son necesarias las luchas en defensa de un derecho de los trabajadores, los movimientos populares organizados, especialmente en el campo brasileño.

PALABRAS CLAVE: Educación Rural. Escuelas de Campo. Presupuesto Federal. Movimiento de Educación Rural. 
* Possui graduação em Educação Física, Mestrado em Ciência do Movimento Humano pela UFSM, Doutorado em Educação pela Universidade Estadual de Campinas e PósDoutorado na Universidade de Oldenburg Alemanha. Atualmente é professora titular da Universidade Federal da Bahia (UFBA).

** Possui graduação em Ciências Sociais pela Universidade do Planalto Catarinense, Mestrado em Educação e Trabalho pela UFSC, Doutorado em Educação: História, Política, Sociedade pela PUC-São Paulo. É pós-doutor em Educação do Campo pela Universidade Estadual Paulista Campus de Presidente Prudente. Atualmente é professor associado 3 , do Centro de Educação da UFSC.
$1<$ http://www.brasil.gov.br/governo/2015 /o1/dilma-toma-posse-e-anuncia-lema-donovo-governo-201cbrasil-patria-educadora201d $>$.

\section{INTRODUÇÃO}

A Comissão Pedagógica Nacional (CNP) do Programa Nacional de Educação em Áreas de Reforma Agrária (Pronera), reunida em Brasília-DF, no período de 15 a 18 de julho de 2015, dedicou um tempo considerável de seu trabalho à avaliação da conjuntura internacional e nacional para precisar o que fazer frente a sua tarefa institucional de avaliar e emitir pareceres a programas e projetos educacionais de caráter formal, a serem executados em parceria entre o Incra/MDA e instituições de ensino, para beneficiar o Plano Nacional de Reforma Agraria (PNRA). Destacamos duas dimensões da problemática educacional brasileira que consideramos relevantes pelas inter-relações que estabelecem. Os cortes no orçamento ocorridos no início de 2015 e o fechamento de escolas do campo, que vêm ocorrendo nos últimos anos no Brasil. Do primeiro problema, destacamos a demonstração dos impactos orçamentários; e do segundo, as táticas para enfrentar nas comarcas - nos municípios, os dispositivos utilizados para o fechamento de escolas e a possibilidade de reversão do processo.

\section{A PÁTRIA EDUCADORA - QUE EDUCAÇÃO? PARA QUE PROJETO DE NAÇÃO? COM CORTES ORÇAMENTÁRIOS?}

A presidente Dilma Rousseff assumiu o seu segundo mandato em primeiro de janeiro de 2015. Adotou, na ocasião, o lema "Pátria Educadora". Fez alegando que a Educação seria a prioridade das prioridades no Brasil, e buscaria em todas as ações do governo um sentido formador. Do discurso da presidenta em sua posse, contam frases como a que seguem.

Democratizar o conhecimento significa universalizar o acesso a um ensino de qualidade em todos os níveis - da creche à pós-graduação; significa também levar a todos os segmentos da população - dos mais marginalizados, aos negros, às mulheres $\mathrm{e} a$ todos os brasileiros a educação de qualidade. Ao longo deste novo mandato, a educação começará a receber volumes mais expressivos de recursos oriundos dos royalties do petróleo e do fundo social do pré-sal. Assim, à nossa determinação política se somarão mais recursos e mais investimentos. (ROUSSEFF, 2015, s/p).

Na sequência deste fato, a Secretaria de Assuntos Estratégicos da Presidência da República, na pessoa de Roberto Mangabeira Unger, sem o Ministro da Educação Renato Janine Ribeiro, apresenta um documento, como assessor da presidenta, que foi muito criticado não somente pela imprensa, mas por intelectuais e autoridades da 
${ }^{2}$ FONTE: Ministério do Planejamento.

área da educação. Além das críticas pela falta de diálogo entre ministérios, o documento foi criticado por não levar em conta o Plano Nacional de Educação, apesar de esse PNE, aprovado em 2014, ter um grande caráter privatista que deve ser profundamente criticado e alterado.

O slogan do governo federal "Pátria Educadora" está em prática e nos resta perguntar: que educação é esta que nos coloca submissos à lógica perversa do capital e à sua irracionalidade com lucros, lucros e mais lucros em detrimento da vida humana digna e de um projeto de nação que supere o capitalismo? Que educação é essa que exige da classe trabalhadora que pague o ônus de uma crise que não foi ela que gerou?

Na sequência do discurso de posse, os cortes orçamentários, o ajuste fiscal e a política econômica altamente destrutiva das forças produtivas do Brasil começaram a operar. Em resposta do governo Brasileiro à conjuntura de crise internacional, a exemplo do que vem ocorrendo em outros países, em especial na Europa, onde a Grécia é o caso mais emblemático, nos cabe perguntar: existiria outra política econômica possível de ser adotada? Os debates econômicos, principalmente advindos de um horizonte histórico socialista, demonstram que sim.

\section{OS CORTES NO ORÇÃMENTO DA UNIÃO: OS CORTES NA EDUCAÇÃO}

Entre as constatações gravíssimas da conjuntura econômica do Brasil, no primeiro semestre de 2015 contam dois fatos gravíssimos: cortes no orçamento da educação e fechamento de escolas do campo.

A política econômica tem relação com a implementação do ajuste fiscal, para promover superávit primário, que implicou em cortes no orçamento geral da união atingindo a todos os ministérios, em especial o Ministério da Educação (19\% de cortes) e o Ministério de Desenvolvimento Agrário (49\% de cortes) ${ }^{2}$.

Reverter os cortes, principalmente, os que atingem políticas sociais vitais para que se efetive a concepção de política de uma Pátria Educadora emancipatória e não empobrecida e submissa, parece-nos crucial e vital para a classe trabalhadora.

Uma necessidade política que se impõe perante os fatos e que reivindicamos juntamente com os servidores públicos federais, neste momento histórico em que eclodem e crescem a insatisfação da população em geral e em especial da classe organizada em centrais sindicais e movimentos populares reivindicatórios, é a reversão dos cortes.

O gráfico a seguir, advindo do Ministério do Planejamento, demonstra com números os impactos em cada ministério, decorrente dos cortes orçamentários. 
44 PÁTRIA EDUCADORA E FECHAMENTO DE ESCOLAS DO CAMPO: O CRIME CONTINUA

\section{CORTE NOS MINISTÉRIOS}

Governo anunciou redução de $R \$ 69,9$ bilhões no Orçamento

DE ONDE VEM O CORTE

Veja o quanto cada ministério contribuiu com o corte do governo
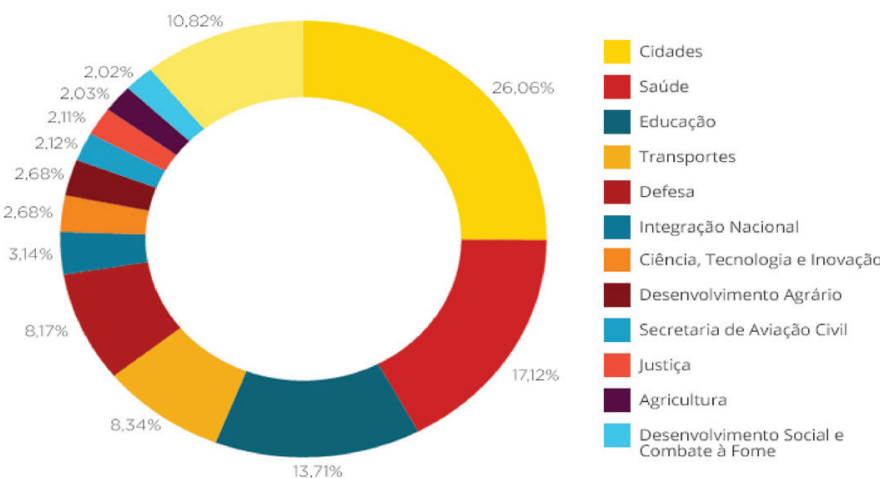

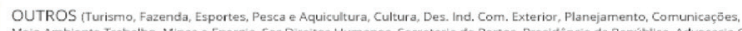

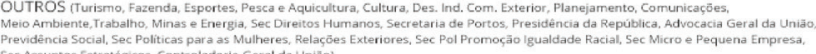

ORÇAMENTO MAIS MAGRO

Veja como era e como ficou o orçamento dos ministérios (em milhöes de reaiss)

COMOERA COMOFICOU PERDEUT\%

Se Pol Promoçăo Igualdade Racial

Sec Micro e Pequena Empresa

Sec Assuntos Estratégicos

Controladoria-Geral da Uniäo

Sec Polliticas Para as Mulheres

Sec Direitos Humanos

Pesca eqquicultura

dvocacia Geral da Uniara

Turismo

Planejamento

Trabalho

Meio Ambiente

cretaria de Portos

Des. Ind. Com. Exterio

Comunicaçôes

Relaçōes Exteriores

Des. Agráric

Previdência Socia

Sec. Aviação Civil

Agricultura

Justiça

Integraçăo Nacional

Fazenda

Ciência, Tecnologia e Inovaçăo

Transportes

Defesa

è àme

Educaçăo

saúde

68

\begin{tabular}{|l|l|l|}
\hline 83 & 30 & $56 \%$ \\
\hline 83 & $35 \%$ \\
\hline
\end{tabular}

\begin{tabular}{|l|l|l|}
\hline 67 & 55 & $18 \%$ \\
\hline
\end{tabular}

249

736

503
1.821

140

$140 \quad 44 \%$

.

$54 \%$

$8 \%$

\begin{tabular}{|l|l|}
\hline 350 & $30 \%$ \\
\hline 476 & $74 \%$ \\
\hline
\end{tabular}

\begin{tabular}{|l|l|}
\hline 476 & $74 \%$ \\
\hline 749 & $24 \%$ \\
\hline
\end{tabular}

$24 \%$

$30 \%$

$30 \%$
$26 \%$
$26 \%$

$26 \%$

$33 \%$

$31 \%$

$23 \%$

$3 \% 5$

$49 \%$

$6 \%$

$39 \%$

$38 \%$

$28 \%$

310

$31 \%$
$38 \%$
$24 \%$

$25 \%$

$25 \%$

$54 \%$

$25 \%$

$4 \%$

\begin{tabular}{|c|c|c|}
\hline 48.813 & 39.383 & $19 \%$ \\
\hline 103.276 & 91.503 & $11 \%$ \\
\hline 6 & 6 & 0 \\
\hline
\end{tabular}

O que o governo promete preservar no orçamento

Bolsa Familia
O que o governo, mesmo com o orçamento menor, promete priorizar:

Sistema Único de Saúde

Mais Médicos

Farmácia Popular

Minha Casa Minha Vida

Obras em andamento de saneamento e mobilidade

Combate à crise hidrica

Obras de rodovias e ferrovias e portos

Ampliação de aeroportos prioritários

Plano Nacional de Banda larga 
Os dados demonstram que o Governo cortou 69,9 bilhões do orçamento da União e que esses cortes atingirão, principalmente, as políticas sociais.

Com restrições orçamentárias desta monta, programas e projetos serão cortados, diminuídos, encerrados, determinando a continuidade do que poderia estar dando certo e, ainda, a inviabilidade do funcionamento de instituições como as universidades que vêm sendo parceiras na implementação de programas de governo que beneficiam as populações do e no campo.

A tática que vem sendo demonstrada pela classe trabalhadora organizada é reagir, com mobilizações, greves, paralisações e outras formas de manifestações, opondo-se ao Plano Econômico Dilma/Levy.

Reconhecemos que, somente com a alteração da correlação de forças, esses planos, que na Europa são de nominados de Planos de Austeridade, poderão ser detidos e revertidos. Esses planos têm um propósito: beneficiar o capital e suas taxas de lucro, em especial o setor especulativo da economia, o setor rentista. A luta de classes está posta e acirrada; e os trabalhadores, reagindo, valendo-se de seus instrumentos de luta. As greves dos setores públicos - federal, estadual e municipal - são evidências disso. Os cortes acentuarão as medidas de impacto nos serviços públicos, entre eles a Educação.

\section{O FECHAMENTO DE ESCOLAS DO CAMPO}

O problema do fechamento das escolas do campo que vem ocorrendo nos últimos 10 anos, tende a se acentuar frente a atual política recessiva e de cortes orçamentários. O fechamento de escolas do campo vem sendo denunciado como um crime contra a nação brasileira.

Considerando que a Educação tem sua especificidade e natureza delimitada ontologicamente nos fundamentos e princípios que possibilitam nos tornarmos seres humanos, fechar escolas representa um violento ataque à própria humanização da população da nação brasileira. Configura-se um crime contra uma nação e sua classe trabalhadora, em especial aos povos do campo, florestas e águas.

Contra isso, colocamo-nos com veemência, recorrendo não só a argumentos relacionados com a ontologia do ser social, da política emancipatória da vida humana, que necessita do acesso permanente à educação escolarizada para o desenvolvimento humano, mas a todo o aparato legal, de direitos, existente, para defender a reversão do quadro alarmante de fechamento de escolas e, assim, ao invés de as escolas do campo serem fechadas, elas sejam instaladas, ampliadas em todos os graus, níveis e modalidades, permitindo o acesso de todos os que residem no campo, garantido a permanência, o percurso educativo com qualidade e a conclusão exitosa da escolarização até o seu mais elevado patamar. 
${ }^{3}$ II PNERA - Relatório da II Pesquisa nacional sobre educação na reforma Agrária. INCRA. PRONERA. UNESCO. UNESP. IPEA. Secretaria de Assuntos estratégicos. MDA. 2015.
${ }^{4}$ PNAE - Programa Nacional De Alimentação Escolar; PNLD - Programa nacional do Livro Didático; PNATE - Programa Nacional de Transporte escolar; Caminho da Escola; PDDE - Programa Dinheiro Direto na escola.
Sobre fechamento de escolas, os dados do Censo Escolar Inep/MEC, assim como os dados do II PNERA - Pesquisa Nacional sobre a Educação na Reforma Agrária $^{3}$-, demonstram que ao longo da última década, o número de escolas do campo brasileiras fechadas é enorme. As escolas foram reduzidas em 31,46\%, ou seja, 32.512 unidades foram fechadas. Com o fechamento de escolas, não existe a possibilidade de enfrentamento dos gravíssimos problemas que afligem a Pátria que se quer Educadora.

a) O analfabetismo - de acordo com levantamentos da Unesco, o Brasil é o oitavo país com a maior população adulta de analfabetos no planeta, 38\% dos analfabetos latino-americanos são brasileiros. Dos 36 milhões de adultos analfabetos na América Latina, 38,5\% são brasileiros. São cerca de 14 milhões de pessoas num país que abriga $34,2 \%$ da população latino-americana. O dado levantado entre 2005 e 2011 consta do relatório "Educação para todos", divulgado pela Organização das Nações Unidas para a Educação, a Ciência e a Cultura (Unesco). Dados da Pesquisa Nacional por Amostra de Domicílios (PNAD) coletados em 2012 mostram que a taxa de analfabetismo da população com 15 anos ou mais teve leve alta entre 2011 e 2012, passando de 8,6\% para 8,7\%. Esses dados nos revelam que o Brasil não cumprirá a meta firmada na Organização das Nações Unidas (ONU) de 6,7\% até 2015.

b) Acesso e permanência nas escolas do campo - o relatório sobre "Educação para todos no Brasil 2000-2015", editado em 2014, demonstra “o que se alcançou" com a educação na primeira infância, na educação primária, na alfabetização de adultos, com estratégias relacionadas ao estabelecimento de outro marco legal, com planejamentos e formas de financiamento, com políticas e programas suplementares, como o PNAE, PNLD, PNATE, PDDE 4 e outros 17 programas, que ainda não deram conta de reverter o quadro alarmante do não acesso e da não permanência exitosa de crianças e jovens nas escolas, em especial no campo.

c) Estrutura e financiamento das escolas do campo - ainda recorrendo ao o relatório sobre "Educação para todos no Brasil - 2000-2015", editado em 2014, bem como ao II PNERA, vamos constatar que o Fundeb, o salário educação, o Fundo Nacional de Desenvolvimento da Educação (FNDE), o pagamento do piso salarial dos professores, entre outras medidas, ainda são insuficientes para garantir a infraestrutura e o bom funcionamento das escolas, o que requer medidas estruturantes para que a escola do campo avance e cumpra a sua função social de garantir a crianças, jovens e adultos do campo o acesso ao conhecimento científico, clássico para que sejam desenvolvidas as funções psíquicas superiores no âmbito do currículo escolar. 
Com base nesses dados, a Comissão Pedagógica Nacional (CPN) do Pronera cumpriu com o seu dever de alertar a todos os setores e âmbitos da sociedade brasileira, em especial a classe trabalhadora organizada que, através de movimentos populares, sindicais e político-partidários, vem defendendo e reivindicando a educação do campo laica, de qualidade, socialmente referenciada, como direito de todos e dever do Estado. Cabe a nós, intelectuais orgânicos situados ombro a ombro com a classe trabalhadora, denunciar este crime.

\section{O QUE FAZER?}

Constatar, explicar, alertar, conclamar e propor formas de enfrentamento é também nosso propósito neste texto. Alertar e conclamar os que estão na luta pela reforma agrária popular, que têm em si um modelo de desenvolvimento agrário que defende a agroecologia, a agricultura familiar e o campesinato. Mais do que nunca é necessário resistir, lutar e avançar frente a esse crime que continua sendo executado - o crime de fechar escolas do campo. Este é um crime contra a nação brasileira que continua e precisa ser interrompido e revertido.

A última lista divulgada pelo MEC (INEP) aponta que 4.084 escolas municipais e estaduais foram fechadas no decorrer de 2014, quase absolutamente todas no campo. E foi instituída uma Lei Federal em 27 de março do mesmo ano para coibir esse ato autoritário, abusivo, discricionário e, por fim, criminoso, que vem sendo praticado por autoridades educacionais em quase todos os estados e municípios brasileiros.

Veja-se o teor da Lei no 12.960 , de 27 de março de 2014:

Altera a Lei no 9.394, de 20 de dezembro de 1996, que estabelece as diretrizes e bases da educação nacional, para fazer constar a exigência de manifestação de órgão normativo do sistema de ensino para o fechamento de escolas do campo, indígenas e quilombolas.

\section{A PRESIDENTA DA REPÚBLICA}

Faço saber que o Congresso Nacional decreta e eu sanciono a seguinte Lei:

Art. 10 O art. 28 da Lei no 9.394, de 20 de dezembro de 1996, passa a vigorar acrescido do seguinte parágrafo único:

Art. 28. Parágrafo único. O fechamento de escolas do campo, indígenas e quilombolas será precedido de manifestação do órgão normativo do respectivo sistema de ensino, que considerará a justificativa apresentada pela Secretaria de Educação, a análise do 
diagnóstico do impacto da ação e a manifestação da comunidade escolar. (NR)

Art. $2^{\mathrm{o}}$ Esta Lei entra em vigor na data de sua publicação.

Brasília, 27 de março de 2014; $193^{\circ}$ da Independência e $126^{\circ}$ da República.

Essa lei foi conquistada pelo Movimento Nacional de Educação do Campo, com o mote "Fechar Escola é Crime", e contrariou os interesses de gestores locais de educação (estados e municípios). Em geral, esses gestores contrariados, como quem faz de conta que não sabe da lei, continuam com a mesma prática. E é regra também não cumprirem a lei e dizerem que não o fazem por pura incapacidade orçamentária, visto que o custo/aluno/qualidade das escolas do campo é mais alto que a média. E na sequência muitos tentam convencer o interlocutor - do Movimento Social, quando o diálogo ocorre - de que a culpa do crime praticado é do sistema federativo, que impõe aos governos locais as obrigações sem a devida cobertura orçamentária.

Ora, em que pese ser evidente existir uma assimetria na relação entre os entes federados do Estado brasileiro, que atribui maior obrigação aos que têm menor poder de resolução e vice-versa, ou seja, empurra mais encargo ao município, que está na ponta do sistema, não constitui papel das organizações e dos movimentos sociais assumir como seus os problemas daí decorrentes. Senão, o que nos cabe é exigir que o aparelho estatal brasileiro se organize, por meio de boa gestão do poder político que é conferido ao conjunto dos servidores públicos do País, no sentido de cumprir aquilo que é determinado como direito social e direito humano de todo cidadão, sem exceção alguma. Aliás, essa determinação não está apenas nas leis estritamente nacionais brasileiras, mas na forma de compromissos no âmbito do Direito Público Internacional. E os parceiros signatários de compromissos internacionais firmados também pelo Brasil, por exemplo, Unidas (1947), a Carta de Jomtièn, de Educação para Todos (1990), a Carta de Santo Domingos (2000) etc., não perguntam se os municípios brasileiros ou os estados federados cumpriram as metas assumidas, se o seu "sistema de colaboração" funciona ou não. Querem, sim, saber se o Estado Nacional brasileiro cumpre com os compromissos preestabelecidos.

De toda maneira, ousamos incentivar os gestores locais, especialmente os dirigentes municipais de educação, a empreenderem lutas internas na relação dos entes federados por fundos públicos diferenciados para o tratamento da questão das escolas do campo. É evidente que fechar ou não uma escola existente no campo ou, então, abrir ou não uma nova escola nesse meio é questão que deve ser tratada de forma articulada com outra questão, a do financiamento. 
5 Disponível em: <http://educanp.weebly. com/uploads/1/3/9/9/13997768/pacto_ da_educao_do_campo_-_ltima_verso_2. pdf $>$. Acesso em: 03 nov. 2015.
Nesse sentido, cabe dizer que a Lei do Fundeb, de no 11.494/2007, hoje atribui a ponderação de 0,15 (15\%), a maior por estudante matriculado em escola do campo, por acordo entre MEC, Consed e Undime - que se reúnem anualmente para definir os novos valores -, e pode chegar até um patamar máximo permitido, que é de 0,30 (30\%). Ousamos, pois, sugerir que a Undime possa assumir e defender a proposta junto ao Ministério da Educação (MEC) e ao Conced de elevação da ponderação do Fundeb para os alunos de escolas do campo.

Em tempo: o Conselho de Secretários de Estado da Educação (Consed) já se manifestou a favor desta e de outras proposições no documento que enviou ao MEC em 2008, com o nome de "Pacto para o Desenvolvimento da Educação Campo". ${ }^{5}$

Veja-se que no espírito da Lei do Fundeb, bem como, e de forma mais evidente, da Lei do fechamento de escolas (no $12.960 / 2014$ ), fica patenteada a necessidade e a disposição da sociedade brasileira de preservar e valorizar os processos educativos dos povos do campo no próprio campo, como de interesse geral da Nação, ainda que tal feito demande mais fundos públicos. E esse "espírito da lei" é transformado em compromisso explícito pelos Secretários de Estado da Educação no referido "Pacto do Consed", quando dizem:

Defendemos que a sociedade brasileira, especialmente aqueles que vivem nas cidades, e o Estado brasileiro devem se responsabilizar e assumir esse custo financeiro imediatamente superior, com vistas à busca da necessária equidade e intercomplementaridade na relação cidade-campo, que implica a busca do alcance real de um processo de desenvolvimento sustentável”. (s/d, p. 4).

E, no mesmo documento, os Secretários de Estado são ainda mais claros ao firmarem que:

Somos conscientes de que o custo médio por aluno/ano na Educação do Campo, mantido um grau de qualidade equivalente ao urbano, será superior a este, o que decorre de diversos fatores como, por exemplo, da população rarefeita, determinando longas distâncias e uma relação numérica de alunos por professor e por escola menos concentrada. Mais alto ainda será o custo para compensar o déficit histórico acumulado no que concerne à educação dos povos do campo, tanto em termos de quantidade quanto de qualidade. Entendemos, todavia, que a superioridade desses custos se revela tão somente na estrita contabilidade econômico-financeira imediata, tais são os altos custos humanos e mesmo econômicos do êxodo rural involuntário e das concentrações urbanas desordenadas. (s/d. p. 4). 
6 <http://www.anped.org.br/forum/index. $\mathrm{php}$ ? $\mathrm{p}=/$ discussion/4/acesse-os-arquivosdo-documento-patria-educadora-da-sae>.

7 <http://www.histedbr.fe.unicamp.br/navegando/glossario/verb_c_plano_naciona_de_educacao\%20.htm $>$. Verbete elaborado por Lalo W. Minto PNE da Sociedade Brasileira. Documento-referência da política educacional brasileira, para todos os níveis de governo. Contempla um diagnóstico da educação no País e, a partir deste, apresenta princípios, diretrizes, prioridades, metas e estratégias de ação para enfretamento dos problemas educacionais do País. Tradicionalmente, os Planos educacionais vêm sendo elaborados de forma centralizada pelos governos brasileiros, a cargo de gabinetes ministeriais ou de comissões contratadas para esse fim, sem debates ou participação dos setores sociais envolvidos com a educação. Na atual legislatura, o PNE está referido no Art. 214 da Constituição Federal de 1988, que determina a sua elaboração de acordo com alguns princípios fundamentais. Já a sua regulamentação foi determinada apenas com a Lei de Diretrizes e Bases da Educação Nacional (LDB, 1996), que deixou à cargo da União, em colaboração com Estados e Municípios, a incumbência de elaborar o PNE, que foi aprovado pela Lei $n$ o 10.172 , de 09/01/2001. Historicamente, foi com o chamado movimento renovador, nos anos 1920-1930, que se concebeu, pela primeira vez no Brasil, a ideia de um Plano Nacional de Educação. O "Manifesto dos Pioneiros da Educação Nova”, de 1932, assinado por um seleto grupo de educadores, foi o documento que sintetizou as ideias desse movimento e estabeleceu a necessidade de um plano nesses moldes. Na legislação educacional, foi na Constituição Federal de 1934, Art. 150, que apareceu a primeira referência ao PNE, mas sem estar acompanhado de um amplo levantamento e estudo sobre as necessidades educacionais do País. Para o estudo do Plano Nacional de Educação, é fundamental a consulta ao Plano Nacional de Educação - Proposta da Sociedade brasileira (1997), consolidado na Plenária de Encerramento do II Congresso Nacional de Educação, CONED, Belo Horizonte/MG, 1997. Igualmente fundamental é consultar a Lei no 10.172, de 09/01/2001, que aprovou o PNE. Disponível em: <http://www.prolei. inep.gov.br/prolei/pesquisar.doc) $>$. Acesso em: 3 nov. 15. Para uma crítica do atual PNE, ver também Ivan Valente e Roberto Romano, "PNE: Plano Nacional de Educação ou Carta de intenção?” (2002). Sobre o PNE e o movimento renovador, ver Otaíza de Oliveira Romanelli, "História da educação no Brasil (1930/1973)" (1978). Sobre o PNE aprovado em 2014, ver as críticas de Luiz Carlos de Freitas, disponível em; <http://revistaeducacao.com.br/textos/ noticias/pesquisador-critica-metas-do-pne-que-estimulam-a-meritocracia-332693-1. asp >; e de Roberto Leher, "Plano Nacional de Educação: notas críticas": <https://plus. google.com/111962320599082246663/ posts/7T9KmBBufFr $>$.
Enfim, fica evidente que a prática de se fechar escola no e do campo não apenas contraria princípios consignados em leis, que embasam uma sociedade equilibrada, mas contraria até a promessa de importantes setores da gestão da educação pública. Só está faltando que esses princípios e promessas se cumpram.

Enquanto isso não ocorre, propomos que, em cada lugar (município ou estado) onde tenha sido fechada uma ou mais escola do campo, principalmente após a vigência da Lei $\mathrm{n}^{0} \mathbf{1 2 . 9 6 0}$, de 27 de março de 2014, os militantes do Movimento de Educação do Campo - coletivos ou mesmo individuais - exijam que revejam os respectivos processos junto ao órgão correspondente (Conselho Municipal de Educação ou Conselho Estadual de Educação). No mínimo, para averiguar se a lei foi cumprida em todos os seus quesitos. Para essa finalidade, o Ministério Público de cada município, comarca ou estado pode e deve ser acionado para que cumpram suas obrigações em defesa do direito público.

\section{À GUIZA DE CONCLUSÃO}

Defendemos, por fim, que a Educação seja considerada prioridade não somente em discursos presidenciais, que os cortes na Educação sejam revertidos e que a Educação ${ }^{6}$, como obra de construção Nacional e Projeto de Estado, retome os princípios e fundamentos do Plano Nacional de Educação (PNE) da Sociedade Brasileira7, conforme originalmente defendido por Florestan Fernandes, perante o parlamento brasileiro, conforme destaca Gaudêncio Frigotto no Caderno de Textos Preparatório ao II Encontro Nacional de Educadores e Educadoras da Reforma Agrária8.

\section{REFERÊNCIAS}

BRASIL. Constituição (1988). Constituição da República Federativa do Brasil. Brasília-DF: Senado Federal, 1988.

. Ministério da Educação. Educação Para Todos. 2014. Disponível em: <http://portal.mec.gov.br/index. php?option=com_docman\&view=download\&alias $=15774-$ -ept-relatorio-06062014\&Itemid=30192>. Acesso em: 23 nov. 2015 .

II CONED. Plano Nacional de Educação - Proposta da Sociedade Brasileira. Belo Horizonte-MG, 1997.

II ENCONTRO NACIONAL DE EDUCADORES E EDUCADORAS DA REFORMA AGRÁRIA. Textos para estudos e debates. São Paulo: Expressão Popular. Boletim da Educação - Número 12. Edição Especial. Dezembro de 2014. 
51 PÁTRIA EDUCADORA E FECHAMENTO DE ESCOLAS DO CAMPO: O CRIME CONTINUA

8 II ENCONTRO NACIONAL DE EDUCADORES E EDUCADORAS DA REFORMA AGRÁRIA. Textos para estudos e debates. São Paulo: Expressão Popular. Boletim da Educação - Número 12. Edição Especial. Dezembro de 2014.
II PNERA - Relatório da II Pesquisa nacional sobre educação na reforma agrária. INCRA. PRONERA. UNESCO. UNESP. IPEA. Secretaria de Assuntos Estratégicos. MDA. 2015.

ONU/UNESCO. Dados estatísticos sobre o Brasil. Disponível em: <http://www.unesco.org/new/pt/brasilia/ about-this-office/unesco-resources-in-brazil/statistics/>. Acesso em: 23 nov. 2015. 